\title{
Dimensionless analysis of transient temperature field of surrounding rock in roadway based on Finite Volume Method
}

\author{
Hao Wang*, Yueping Qin, Xinxing Han, Enlai Liu, Zhanyuan Dong \\ School of Resources and Safety Engineering, China University of Mining and Technology, Beijing 100083, China
}

Corresponding Author Email: wanghao6755@126.com

https://doi.org/10.18280/ijht.360312

Received: 24 October 2017

Accepted: 15 December 2017

\section{Keywords:}

similar simulation experiment, transient, roadway, dimensionless, unstable heat transfer criterion

\begin{abstract}
The similar simulation experiment platform for the temperature field of surrounding rock in roadway was established based on similarity theory. It was made possible to verify simulation results of the Finite Volume Method. In order to reveal the heat dissipation rules in roadway, the mathematical model of transient temperature field for the surrounding rock in roadway was established, and dimensionless parameters were introduced into the model to make the model non-dimensional. The Finite Volume Method based on triangular mesh was used to discretize the dimensionless equation and the dimensionless temperature distribution for the transient temperature field of surrounding rock in roadway was obtained. At the wall face in roadway, the dimensionless temperature decreases gradually with the increase of Biot coefficient and Fourier coefficient, and finally tends to a certain value. The curves of the unstable heat transfer criterion and the corresponding laws of variation were obtained by further calculation. The numerical results have shown that the unstable heat transfer criterion decreases with the increase of the Fourier number at a constant Biot coefficient, while it increases with the increase of Biot coefficient at a constant Fourier coefficient. The research results in this paper provide a simple and reliable algorithm to determine the unstable heat transfer criterion derived from the corresponding parameter values of an arbitrary transient temperature field of surrounding rock in roadway. For mine cooling technicians, it provides important reference basis to calculate the chilling requirements and study the heat dissipation rules of surrounding rock in roadway.
\end{abstract}

\section{INTRODUCTION}

The heat dissipation quantity for the surrounding rock occupies a large proportion in mine thermal hazard problem, which is more than the sum of heat release of other heat sources. With the depletion of shallow mineral resources in most of the mining areas all over the world, the deep mining is inevitable, and the mine thermal hazards is becoming more and more serious [1-3]. Therefore, mastering the heat dissipation rules of surrounding rock and calculating the heat dissipation quantity of surrounding rock accurately is of great significance for preventing and controlling coal mine thermal disaster accidents, improving mine labor productivity and ensuring the occupational health of workers [4-6].

The deep mine roadway has a great influence on the meteorological environment of the mine due to the long ventilation line, large exposure area and complex ventilation system [7-8]. The research on the temperature field of the surrounding rock in roadway plays a vital role in controlling the thermal pollution of the cold air in the high temperature mine [9-10]. Numerous scholars have studied the distribution characteristics for the temperature field of surrounding rock and the heat exchange rules between the airflow and surrounding rock. Wu et al. made a deep discussion on the temperature variation patterns of surrounding rock, the heat exchange law of the airway, the heat transfer coefficient and mass transfer coefficient under two conditions of drying and moisture [11-12]. Kajzar et al. obtained a new spatial distribution model of primary temperature values for the carboniferous massif from measurements carried out in short boreholes drilled directly into mine workings [13]. Kondjoyan et al. presented a method based on psychrometry for measuring heat and mass transfer coefficients in the case of forced convective exchanges between air and a body surface [14]. Currently, more and more simulation software and calculation methods are applied to the thermal calculation in mines as the development of computer technology. Lowndes et al. presented results of a series of detailed parametric studies analysis conducted on a computer based tunnel climatic prediction model developed at the University of Nottingham [15]. Taraba et al. used software FLUENT to simulate the process of coal self-heating in long wall gob, and paid the main attention to influence factors of oxidation heat [16]. Noureddine et al. studied the mechanism of heat and mass transfer during water evaporation in a two-dimensional steady laminar flow of dry air or air-vapor mixture in a horizontal channel based on finite difference method [17]. Coelho et al. elaborated advances in the discrete ordinates and Finite Volume Method for the solution of radiative heat transfer problems in participating media [18].

The heat dissipating quantity from the surrounding rock in roadway varies with time, and heat exchange between the surrounding rock and the wind flow is a very complicated dynamic process. Usually, this process was defined as unstable heat exchange process which can be expressed by the dimensionless physical parameter [19]. Currently the research 
on the temperature field of the surrounding rock in roadway mainly focuses on the theoretical analysis of calculation for unstable heat transfer coefficient. Unfortunately, neither the wall temperature of surrounding rock nor the unstable heat exchange coefficient between air flow and surrounding rock were easy to be assigned in applications. In addition, few calculation methods with definite physical meaning were used to solve the unstable heat transfer criterion and these issues are still deserved to the further study. The algorithm presented in this paper can quickly and accurately determines the temperature field of surrounding rock and the heat transfer between surrounding rock and air flow. Therefore, this paper carried out the simulation experiment of transient temperature field for the roadway, and then established the mathematical model for transient temperature field, using dimensionless analysis and Finite Volume Method to describe the temperature distribution of surrounding rock and fluctuation law of wall temperature in roadway. Finally, the unstable heat transfer criterion between surrounding rock and air flow in roadway was calculated.

\section{SIMILAR SIMULATION EXPERIMENT}

\subsection{Experimental principle}

The similitude coefficient between original physical model and the similarity model for the temperature field of surrounding rock mainly included as follows: Thermal Diffusion Similar Coefficient Ca, Time Similar Coefficient $C_{t}$ Heat Convection Similar Coefficient $C_{\alpha}$, Size Similar Coefficient $C_{l}$, Thermal Conductivity Similar Coefficient $C_{\lambda}$, Velocity Similar Coefficient $C_{u}$ and so on.

In order to determine the similitude coefficient of physical phenomena, the following dimensionless parameters were introduced:

$$
\left\{\begin{array}{l}
F_{o}=\frac{a \cdot \tau}{r_{0}^{2}} ; B i=\frac{\alpha \cdot r_{0}}{\lambda} ; R=\frac{r}{r_{0}} ; \\
\operatorname{Re}=\frac{\rho u d}{\mu} ; \operatorname{Pr}=\frac{\mu c_{p}}{\lambda_{f}} ; N u=\frac{\alpha d}{\lambda_{f}}
\end{array}\right.
$$

where, $F_{O}$ is the Fourier coefficient; $a$ is the thermal diffusivity of surrounding rock, $\mathrm{m}^{2} / \mathrm{s} ; \tau$ is the time, $\mathrm{s} ; r_{0}$ is the characteristic radius of tunnel, $\mathrm{m} ; B i$ is the Biot coefficient; $\alpha$ is the thermal convectivity of surrounding rock, $\mathrm{W} /\left(\mathrm{m}^{2} \cdot{ }^{\circ} \mathrm{C}\right) ; \lambda$ is the heat conductivity coefficient of surrounding rock, $\mathrm{W} /\left(\mathrm{m} \cdot{ }^{\circ} \mathrm{C}\right) ; R$ is the dimensionless radius; $r$ is the roadway radius, $\mathrm{m}$; $R e$ is Reynolds coefficient; $\rho$ is the airflow density, $\mathrm{kg} / \mathrm{m}^{3} ; u$ is the velocity of flow, $\mathrm{m} / \mathrm{s} ; d$ is the roadway diameter, $\mathrm{m} ; \mu$ is the dynamic viscosity coefficient, $\mathrm{Pa} \cdot \mathrm{s} ; \mathrm{Pr}$ is the Prandtl coefficient; $C_{p}$ is the specific heat of constant pressure, $\mathrm{J} /(\mathrm{kg} \cdot \mathrm{K}) ; \lambda_{f}$ is the heat conductivity coefficient of air flow, $\mathrm{W} /\left(\mathrm{m} \cdot{ }^{\circ} \mathrm{C}\right) ; N u$ is the Nusselt coefficient

\subsubsection{Similitude coefficient of surrounding rock in roadway}

The same physical phenomena are of the same properties, and their physical processes are subject to the same natural law. The equation describing this phenomenon is the same in its form and content. According to the similarity principle [20], as long as the corresponding characteristic parameters in prototype and model are equal, the simulation experiment and the physical phenomena of prototype are necessarily similar.
Therefore, the condition that the model is similar to the prototype is derived from $F_{O}=F_{O}{ }^{\prime} ; B i=B i^{\prime} ; R=R^{\prime}$.

$\frac{a \cdot \tau}{r_{0}^{2}}=\frac{a^{\prime} \cdot \tau^{\prime}}{\left(r_{0}{ }^{\prime}\right)^{2}} ; \frac{\alpha \cdot r_{0}}{\lambda}=\frac{\alpha^{\prime} \cdot r_{0}{ }^{\prime}}{\lambda^{\prime}} ; \frac{r}{r_{0}}=\frac{r^{\prime}}{r_{0}{ }^{\prime}}$

The similitude coefficient should satisfy the following relations.

$\frac{C_{a} C_{t}}{C_{l}^{2}}=1 ; \frac{C_{\alpha} C_{l}}{C_{\lambda}}=1$

\subsubsection{Similitude coefficient of air flow in roadway}

The factors influencing the coefficient $\alpha$ are $\rho, u, \mu, d, C_{p}$ and $\lambda_{f}$. Therefore, the coefficients affecting similitude coefficient $C_{a}$ are $\operatorname{Re}$ coefficient, $\operatorname{Pr}$ coefficient, $N u$ coefficient. In the same way, the condition that the model is similar to the prototype as follows according to the similarity principle.

$$
\frac{\rho u d}{\mu}=\frac{\rho^{\prime} u^{\prime} d^{\prime}}{\mu^{\prime}} ; \frac{\mu c_{p}}{\lambda_{f}}=\frac{\mu^{\prime} c_{p}{ }^{\prime}}{\lambda_{f}{ }^{\prime}} ; \frac{\alpha d}{\lambda_{f}}=\frac{\alpha^{\prime} d^{\prime}}{\lambda_{f}{ }^{\prime}}
$$

The medium that through the model and the prototype was the air, so the value of $\rho, \mu, C_{p}, \lambda_{f}$ in the prototype were respectively equal to that in the model and as well as $P r$ coefficient. $N u$ coefficient was the function of $R e$ coefficient and $\operatorname{Pr}$ coefficient according to the similarity theory of convective heat transfer. If $R e$ coefficient and $P r$ coefficient was respectively equal in the prototype and model, $N u$ coefficient was necessarily equal. Therefore, make the $R e$ coefficient in the model equal to that in the prototype was enough for ensuring the similarity. In addition, $B i=B i^{\prime}$ was deduced from the condition that boundary conditions of thermal conductivity of surrounding rock were similar. Therefore, the relation of characteristic coefficient describing similar physical phenomena is obtained as follows:

$$
\left\{\begin{array}{l}
\frac{\rho u d}{\mu}=\frac{\rho^{\prime} u^{\prime} d^{\prime}}{\mu^{\prime}} \Rightarrow u d=u^{\prime} d^{\prime} ; \frac{\alpha d}{\lambda_{f}}=\frac{\alpha^{\prime} d^{\prime}}{\lambda_{f}{ }^{\prime}} \Rightarrow \alpha d=\alpha^{\prime} d^{\prime} \\
\frac{\alpha \cdot r_{0}}{\lambda}=\frac{\alpha^{\prime} \cdot r_{0}{ }^{\prime}}{\lambda^{\prime}} \Rightarrow \lambda=\lambda^{\prime}
\end{array}\right.
$$

The similitude coefficient should satisfy the following relations.

$C_{u} C_{l}=1 ; C_{\alpha} C_{l}=1 ; C_{\lambda}=1$

\subsection{Similar simulation experiment platform}

According to the similarity relation equation obtained by above analysis, the similar simulation experiment platform for the temperature field of surrounding rock in roadway was designed, as shown in Figure 1. The platform consists of 3 parts includes airflow parameter control system, main body of roadway model and data monitoring and acquisition system.

Temperature sensors are arranged in the main body of the model, the distance between sensors is $60 \mathrm{~mm}$, and the diagrammatic sketch is shown as Figure 2.

It is an important work to obtain the initial conditions of the temperature field of the surrounding rock and keep the 
boundary condition to be constant in the similar simulation experiment. Before the experiment, observe the temperature value of each measuring point for a period of time, and ensure that the temperature inside the surrounding rock was consistent with that inside the roadway, so as to get the initial condition of the temperature field of surrounding rock. The experiment was not started until the temperature values of the measured points were constant. In order to ensure the continuous stability of boundary conditions in similar simulation experiments, thermal insulation materials were wrapped around the main body of the roadway to reduce the influence of ambient temperature on the experimental results. At the same time, the time and space change laws of surrounding rock in roadway were analyzed in 5 hours.

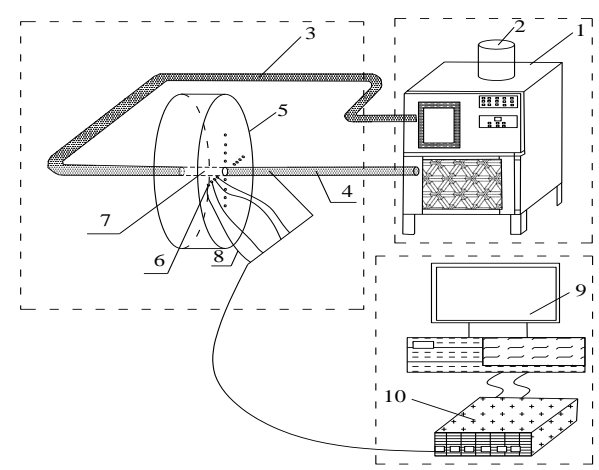

1. Airflow parameter control system; 2. Variable frequency blower; 3. Air inlet pipe; 4. Return air pipe; 5. Main body of roadway model; 6 . Temperature measuring point; 7. Similitude simulation roadway; 8 . Data monitoring system; 9. Computer; 10. Data collector

Figure 1. Sketch of experimental

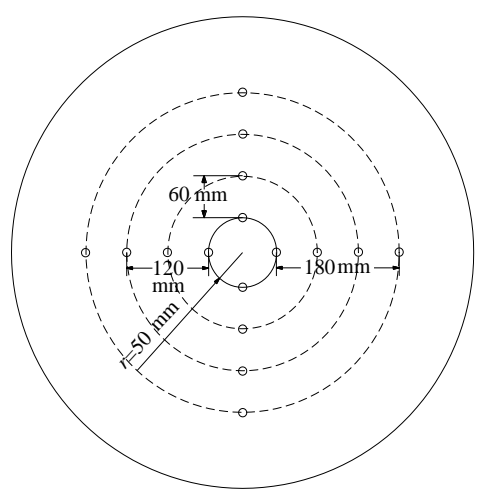

Figure 2. Layout of measuring points

In this paper, the similar materials of surrounding rock were made by mixing gypsum with water in a certain proportion, and adding a proper amount of iron powder to enhance the thermal conductivity of the surrounding rock. Similar materials were placed in the laboratory for determination, and related parameters were obtained, as shown in Table 1.

Table 1. Experimental values of parameters of similar surrounding rock

\begin{tabular}{ccc}
\hline Physical quantity & Value & Unit \\
\hline Density $(\rho)$ & 952 & $\mathrm{~kg} / \mathrm{m}^{3}$ \\
\hline Heat conductivity coefficient $(\lambda)$ & 0.673 & $\mathrm{~W} /\left(\mathrm{m} \cdot{ }^{\circ} \mathrm{C}\right)$ \\
\hline Specific heat of constant pressure $\left(C_{P}\right)$ & 1060 & $\mathrm{~J} /(\mathrm{kg} \cdot \mathrm{K})$ \\
\hline Thermal diffusivity $(a)$ & $6.669 \mathrm{E}-07$ & $\mathrm{~m} / \mathrm{s}$ \\
\hline
\end{tabular}

\subsection{Experimental scheme}

The experiment scheme and parameters were set up in order to obtain the distribution rules for the temperature field of surrounding rock in roadway, as shown in Table 2.

Table 2. Experimental scheme and parameter settings

\begin{tabular}{|c|c|c|c|c|}
\hline Parameters & $\begin{array}{c}\text { Scheme } \\
1\end{array}$ & $\begin{array}{c}\text { Scheme } \\
2\end{array}$ & $\begin{array}{c}\text { Scheme } \\
3\end{array}$ & Unit \\
\hline $\begin{array}{c}\text { Convective } \\
\text { heat exchange } \\
\text { coefficient }\end{array}$ & $\alpha=6.73$ & $\alpha=13.46$ & $\alpha=26.92$ & $\mathrm{~W} /\left(\mathrm{m}^{\left.2 \cdot{ }^{\circ} \mathrm{C}\right)}\right.$ \\
\hline Wind speed & $u=0.2$ & $u=0.48$ & $u=1.14$ & $\mathrm{~m} / \mathrm{s}$ \\
\hline $\begin{array}{l}\text { Airflow } \\
\text { density }\end{array}$ & $\rho=1.29$ & $\rho=1.29$ & $\rho=1.29$ & $\mathrm{Kg} / \mathrm{m}^{3}$ \\
\hline $\begin{array}{c}\text { Dynamic } \\
\text { viscosity } \\
\text { coefficient }\end{array}$ & $\mu=0.144$ & $\mu=0.144$ & $\mu=0.144$ & $\mathrm{E}-06(\mathrm{~Pa} \cdot \mathrm{s})$ \\
\hline $\begin{array}{l}\text { Specific heat } \\
\text { of constant } \\
\text { pressure for } \\
\text { wind }\end{array}$ & $C_{p}=1005$ & $C_{p}=1005$ & $C_{p}=1005$ & $\mathrm{~J} /(\mathrm{kg} \cdot \mathrm{K})$ \\
\hline $\begin{array}{l}\text { Air flow heat } \\
\text { conductivity } \\
\text { coefficient }\end{array}$ & $\begin{array}{c}\lambda_{f} \\
=0.026\end{array}$ & $\lambda_{f}=0.026$ & $\lambda_{f}=0.026$ & $\mathrm{~W} /\left(\mathrm{m} \cdot{ }^{\circ} \mathrm{C}\right)$ \\
\hline $\begin{array}{c}\text { Original } \\
\text { dimensionless } \\
\text { temperature }\end{array}$ & $\Theta=1$ & $\Theta=1$ & $\Theta=1$ & None \\
\hline $\begin{array}{c}\text { Dimensionless } \\
\text { radius of wall }\end{array}$ & $R=1$ & $R=1$ & $R=1$ & None \\
\hline $\begin{array}{c}\text { Fourier } \\
\text { coefficient }\end{array}$ & $F_{O}=5$ & $F_{O}=5$ & $F_{O}=5$ & None \\
\hline $\begin{array}{c}\text { Biot } \\
\text { coefficient }\end{array}$ & $B i=0.5$ & $B i=1$ & $B i=2$ & None \\
\hline
\end{tabular}

\section{MATHEMATICAL MODEL}

\subsection{Differential equations of heat conduction and boundary conditions}

The temperature distribution inside the object is uneven after the roadway wall is exposed. Heat flows from the high temperature place to the low temperature place, forming the heat dissipation of surrounding rock affected by the temperature gradient. There are many factors affecting the heat dissipation of surrounding rock, such as the flow velocity, air temperature, original rock temperature, convective heat transfer coefficient, etc. In order to highlight the relationship among the main influencing factors and simplify the problem, assumptions were obtained as follows: (1) The surrounding rock of roadway is homogeneous and isotropic; (2) The roadway cross section is round, the heat flow direction is radial and the whole process conforms to the Fourier law; (3) The temperature difference of rock mass far away from the wall is zero, and there is no heat flux; (4) The heat transfer condition is same along the axial direction of the tunnel. Finally, the differential equation for the transient heat dissipation of surrounding rock in roadway is deduced according to Conservation of energy and Fourier law. 
$\frac{\partial^{2} T}{\partial x^{2}}+\frac{\partial^{2} T}{\partial y^{2}}=\frac{1}{a} \frac{\partial T}{\partial \tau}$

where, $T$ is surrounding rock temperature, ${ }^{\circ} \mathrm{C}$.

The temperature field of the surrounding rock in roadway was stable invariable before experiment. In the whole process, the temperature of rock mass far away from the wall was constant. The calculation area was shown in Figure 3. According to the above analysis, the initial conditions and boundary conditions for the transient temperature field of surrounding rock in roadway are as follows:

$\left\{\begin{array}{l}T_{\tau=0}=T_{g u} \\ -\left.\lambda \frac{\partial T}{\partial r}\right|_{\Gamma_{1}}=\alpha\left(T_{w}-T_{f}\right) \\ T_{\Gamma_{2}}=T_{g u}\end{array}\right.$

where, $T_{g u}$ is the original rock temperature, ${ }^{\circ} \mathrm{C} ; \Gamma_{1}$ is the inside boundary of surrounding rock; $\Gamma_{2}$ is the outside boundary of surrounding rock; $T_{w}$ is the roadway wall temperature, ${ }^{\circ} \mathrm{C} ; T_{f}$ is the airflow temperature, ${ }^{\circ} \mathrm{C}$.

\subsection{Dimensionless mathematical model}

For roadways in different mining area, the thermal parameters of surrounding rock are different in roadway section radius, original rock temperature, air flow temperature, wind speed and so on. But the physical equation is same for the transient temperature field of surrounding rock, as well as the dimensionless equation. In the dimensionless equation, the number of variables is reduced, and the calculation results are full of universality. In order to establish dimensionless mathematical model for the temperature field of surrounding rock in roadway, introduced these dimensionless parameters as follows:

$X=\frac{x}{r_{0}} ; \quad Y=\frac{y}{r_{0}} ; \quad \theta=\frac{T-T_{f}}{T_{g u}-T_{f}} ; \quad k_{u \tau}=\frac{k_{\tau} \cdot r_{0}}{\lambda}$

where, $X$ is the dimensionless horizontal ordinate; $Y$ is the dimensionless vertical coordinate; $\theta$ is dimensionless temperature; $k_{u \tau}$ is the unstable heat exchange criterion; $k_{\tau}$ is unstable heat transfer coefficient, $\mathrm{W} /\left(\mathrm{m}^{2} \cdot{ }^{\circ} \mathrm{C}\right)$.

The dimensionless parameters of $\mathrm{Eq}(1)$ and $\mathrm{Eq}(9)$ are substituted into $\mathrm{Eq} \mathrm{(7)} \mathrm{and} \mathrm{Eq}$ (8) respectively, and the dimensionless model for the transient temperature field of surrounding rock in roadway can be deduced as follows:

$\frac{\partial}{\partial X}\left(\frac{\partial \theta}{\partial X}\right)+\frac{\partial}{\partial Y}\left(\frac{\partial \theta}{\partial Y}\right)=\frac{\partial \theta}{\partial F_{o}}$

The corresponding initial and boundary conditions are:

$\left\{\begin{array}{l}-\left.\frac{\partial \theta}{\partial R}\right|_{\Gamma_{1}}=\theta_{w} \cdot B i \\ \theta_{F_{o}=0}=1 \\ \theta_{\Gamma_{2}}=1\end{array}\right.$
The heat dissipation quantity for the transient temperature field of surrounding rock in roadway can be calculated by Eq (12) or Eq (13).

$$
\begin{aligned}
& q=\alpha\left(T_{\mathrm{w}}-T_{f}\right) \\
& q=k_{\tau}\left(T_{g u}-T_{f}\right)
\end{aligned}
$$

So, the unstable heat transfer coefficient between roadway and airflow is obtained as follows:

$$
\frac{B i}{k_{u \tau}}=\frac{\alpha}{k_{\tau}} \Rightarrow k_{u \tau}=\theta_{\mathrm{w}} \cdot B i
$$

where, $\theta_{\mathrm{w}}$ is dimensionless temperature of wall surface in roadway.

From Eq (10) and Eq (11), it can be considered that the dimensionless temperature for surrounding rock in roadway is the function of Fourier coefficient, Biot coefficient and dimensionless radius. When $R=1$, the dimensionless temperature is the wall temperature.

$\theta=f(F o, B i, R)$

$\theta_{w}=f(F o, B i)$

The Eq (17) can be obtained by using Green formula after integrating $\mathrm{Eq}(10)$.

$\oint_{l}\left(\frac{\partial \theta}{\partial X} d Y-\frac{\partial \theta}{\partial Y} d X\right)=\iint_{D} \frac{\partial \theta}{\partial F_{o}} d \sigma$

\subsection{The Finite Volume Method based on triangular mesh}

The Finite Volume Method is suitable for solving many problems. The obtained equation can guarantee conservation characteristics of physical quantities such as mass, energy and momentum, and the physical meaning is clear and explicit. Here the paper used the Finite Volume Method to discrete the mathematical model for the transient temperature field of surrounding rock in roadway. In this paper, the triangular element was selected as the basic unit for dividing the calculation area. The whole computing area for the temperature field of surrounding rock in roadway was divided into the collection of triangular elements as shown in Figure 3. The grid size of the triangular element gradually increased in a fixed proportion from wall surface to the deep rock due to the drastic changes of temperature near the wall surface.

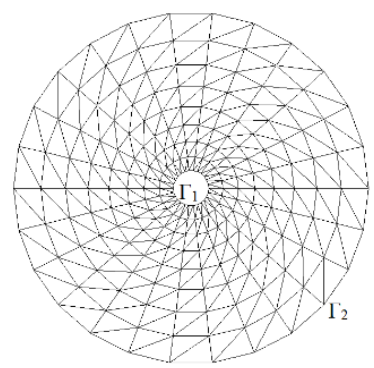

Figure 3. Meshing of computational region and boundary conditions 


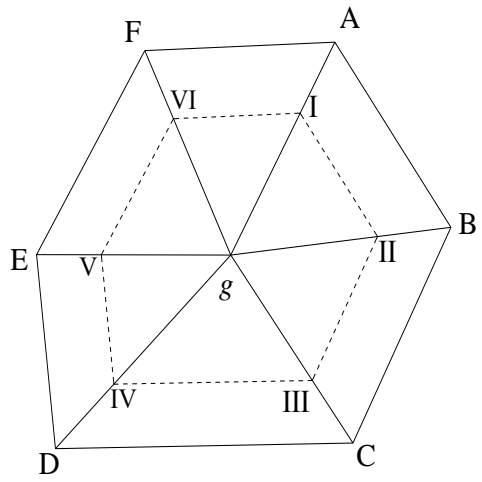

Figure 4. Node control volume

In the computational region, each triangular element was associated with three nodes, each of which was associated with the six adjacent triangular units as shown in Figure 4. In each triangular element, a straight line passing through the center of gravity of any triangle was parallel to the opposite edge of the node g. The control volume with vertices from I-VI is composed of six small triangular elements. Therefore, the discrete equation to the computational region can be obtained as follows:

$\sum_{k=1}^{6}\left(\frac{\partial \theta}{\partial X} \Delta Y-\frac{\partial \theta}{\partial Y} \Delta X-\frac{\partial \theta}{\partial F_{o}} d S\right)=0$

The equation is abbreviated as:

$$
\sum_{e=1}^{k} Q_{l}=0
$$

where, $\Delta X$ and $\Delta Y$ are the projected length on $X$-axis and $Y$ axis of the $k$-th control volume of node g respectively; $S$ is the area of $k$-th control volume; $Q_{l}$ is the contribution of the $k$-th control volume to the energy equation of node $g$.

The energy balance equation with arbitrary internal nodes as the target was established through the above analysis. The contribution for any control volume to the three nodes is expressed in the form of matrix.

$\left[\begin{array}{l}Q_{i} \\ Q_{j} \\ Q_{m}\end{array}\right]=\left[\begin{array}{lll}k_{i i} & k_{i j} & k_{i m} \\ k_{j i} & k_{j j} & k_{j m} \\ k_{m i} & k_{m j} & k_{m m}\end{array}\right]\left[\begin{array}{l}\theta_{i} \\ \theta_{j} \\ \theta_{m}\end{array}\right]+\left[\begin{array}{ccc}n_{i i} & n_{i j} & n_{i m} \\ n_{j i} & n_{j j} & n_{j m} \\ n_{m i} & n_{m j} & n_{m m}\end{array}\right]\left[\begin{array}{l}\frac{\partial \theta_{i}}{\partial F_{o}} \\ \frac{\partial \theta_{j}}{\partial F_{o}} \\ \frac{\partial \theta_{m}}{\partial F_{o}}\end{array}\right]$

In the equation [21]:

$k_{l l}=-\frac{1}{3 S}\left(b_{l}^{2}+c_{l}^{2}\right) ; \quad k_{l n}=k_{n l}=-\frac{1}{3 S}\left(b_{l} b_{n}+c_{l} c_{n}\right) ;$

$n_{l l}=-\frac{20 S}{81} ; \quad n_{l n}=n_{n l}=-\frac{8 S}{81} ; \quad(l, n=i, j, m ; l \neq n)$

$b_{i}=Y_{j}-Y_{m} ; \quad b_{j}=Y_{m}-Y_{i} ; \quad b_{m}=Y_{i}-Y_{j} ;$

$c_{i}=X_{m}-X_{j} ; c_{j}=X_{i}-X_{m} ; c_{m}=X_{j}-X_{i}$;

$S=\frac{1}{2}\left(b_{i} c_{j}-b_{j} c_{i}\right)$
In the same way, the contribution for the boundary element to the two related boundary nodes was calculated. The coefficient matrix is:

$\left[\begin{array}{l}Q_{m} \\ Q_{k}\end{array}\right]=\left[\begin{array}{ll}u_{m m} & u_{m k} \\ u_{k m} & u_{k k}\end{array}\right]\left[\begin{array}{l}\theta_{m} \\ \theta_{k}\end{array}\right]$

In the equation:

$u_{m m}=u_{k k}=\frac{4}{9} l B_{i}, \quad u_{m k}=u_{k m}=\frac{2}{9} l B_{i}$

where, $l$ is the boundary length

The contribution for each element to any node $g$ was calculated, and the linear equation for the any node $g$ was synthesized by unit search. Then, the system of linear equations with unknown quantities was obtained. Finally Gauss elimination method was used to solve the coefficient matrix, and the temperature for the whole region at different time was obtained.

\subsection{Calculation result}

The result was plotted by the software Tecplot, as shown in Figure 5. The dimensionless temperature distribution of surrounding rock in roadway was obtained when the Biot coefficient was 2 and the Fourier coefficient is $0.2,0.5,2$ and 5 respectively.

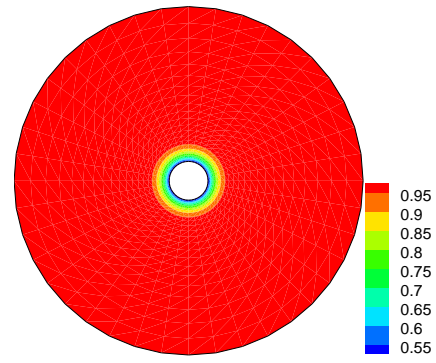

(a) $F_{O}=0.2$

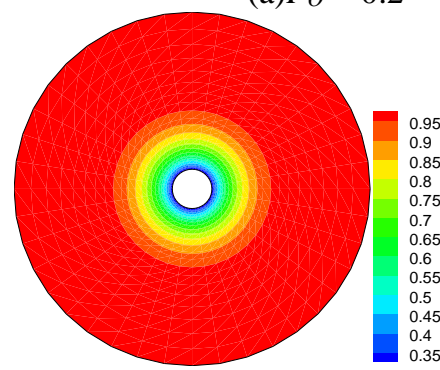

(c) $F_{O}=2$

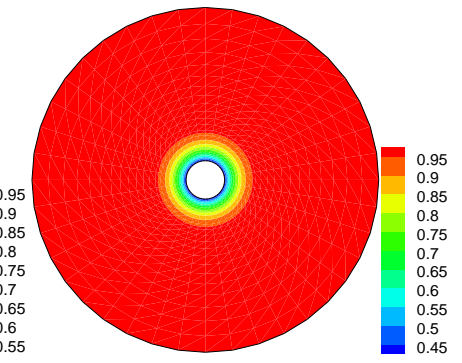

(b) $F_{O}=0.5$

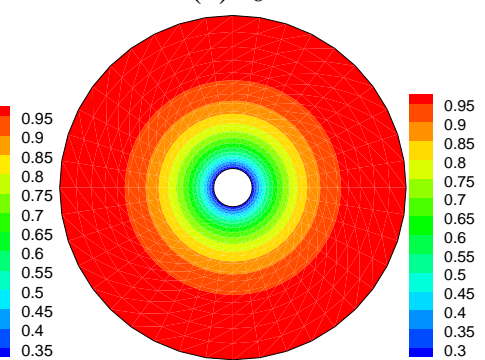

(d) $F_{O}=5$

Figure 5. Dimensionless temperature distribution of surrounding rock in roadway

As shown in Figure 5, there forms a series of cooling rings around the wall surface under the influence of ventilation and cooling. Cooling rings are concentric round and extend to the deep rock. With the extension for the inner zone of the surrounding rock towards deep rock, the dimensionless temperature increases gradually while the dimensionless temperature gradient decreases gradually. It also can be seen from (a)-(d) that the dimensionless wall temperature gradually decreases, while the cooling zone becomes larger with the increase of the Fourier coefficient. 


\section{RESULTS AND DISCUSSION}

\subsection{Comparative analysis of calculation results and experimental results}

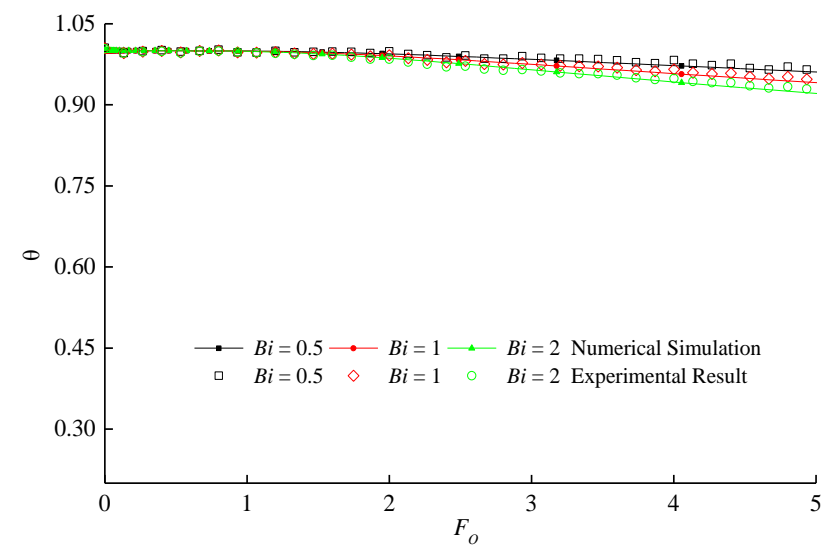

(a) $180 \mathrm{~mm}$ away from the wall surface

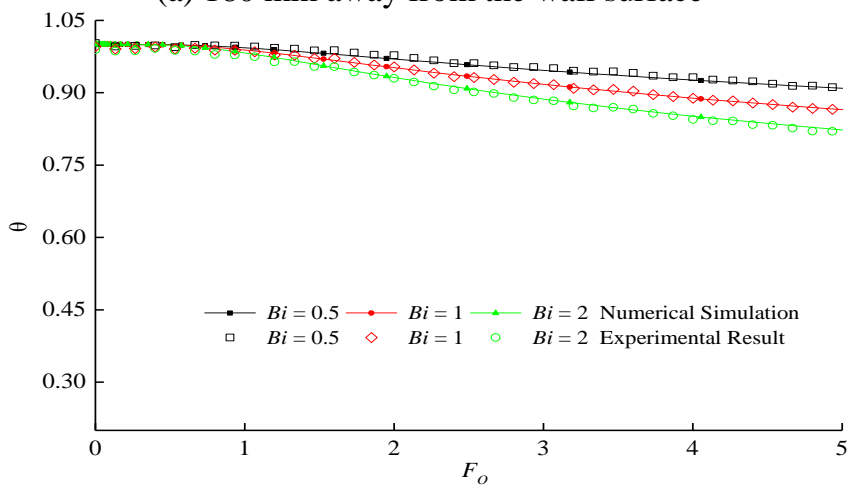

(b) $120 \mathrm{~mm}$ away from the wall surface

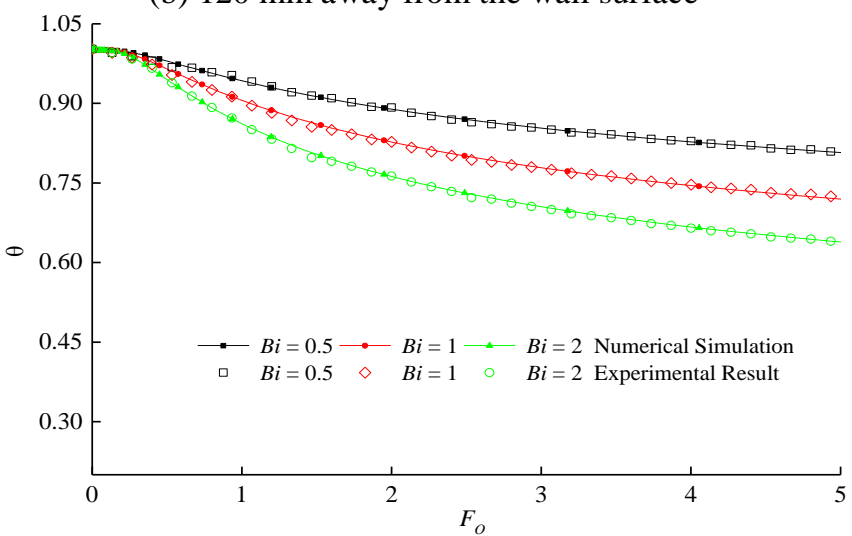

(c) $60 \mathrm{~mm}$ away from the wall surface

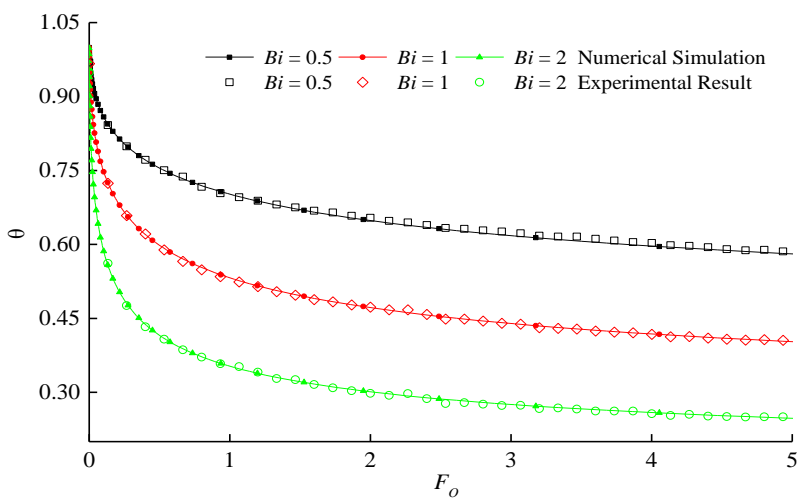

(d) the wall face

Figure 6. Comparison curves between numerical results and experimental data
According to the simulation results and experimental results, we used origin software to draw the variation curve for the dimensionless temperature of surrounding rock in roadway with increasing Fourier coefficient under different values of Biot coefficient. The Figure 6 (a-d) are contrast curve figures between the numerical results and the experimental data.

It can be seen from the Figure 6 that the dimensionless temperature of each position in roadway begins to decrease in different degrees after the ventilation begins. With the increase of Fourier coefficient, the amplitude of variation of dimensionless temperature relative to Fourier coefficient decreases at a constant Biot coefficient. When the Fourier coefficient is same, the larger the Biot coefficient is, the smaller the dimensionless temperature of same location is; Contrast map (a-d) show that the decreasing range for the temperature of the measuring point close to the wall is larger than that far from the wall face. There are some small errors due to the influence of the measuring precision and the placement position of temperature sensors. The experimental data are consistent well with the simulation results, and it verifies the correctness of the Finite Volume Method.

\subsection{Dimensionless temperature distribution of wall face}

As shown in Figure 7, the dimensionless temperature for the wall surface in roadway decreases gradually with the increase of Biot coefficient and Fourier coefficient, and finally tends to a certain value. The larger the Biot constant is, the smaller the dimensionless temperature of wall surface is in roadway when the Fourier constant is same.

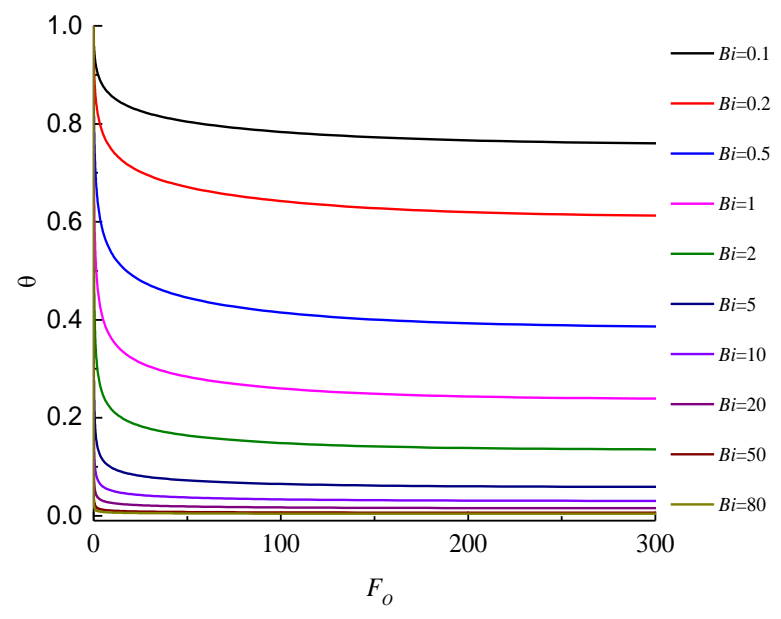

Figure 7. The change curve for temperature of wall face with the increasing Fourier coefficient under different Biot coefficient

\subsection{The unstable heat transfer criterion}

The curve of unstable heat transfer criterion under different Fourier coefficient and Biot coefficient was obtained by using Eq (14) after analyzing the fluctuation law of temperature on the wall surface, as shown in Figure 8.

As shown in Figure 8, the unstable heat transfer criterion decreases with the increase of the Fourier coefficient at a constant Biot coefficient, while the unstable heat transfer criterion increases with the increase of Biot coefficient at a constant Fourier coefficient. The amplitude of variation of the unstable heat transfer criterion relative to the Fourier coefficient increases, with the increase of Biot coefficient. For 
any specific roadway, dimensionless characteristic parameters of it can be figured out and then the unstable heat transfer criterion can be determined according to the above method. The interpolation method is usually used to determine the value of the unstable heat transfer criterion under the circumstances that the calculated parameters are between some two legend values. Finally, we can apply the calculated parameters to deal with the mine heat harm problem.

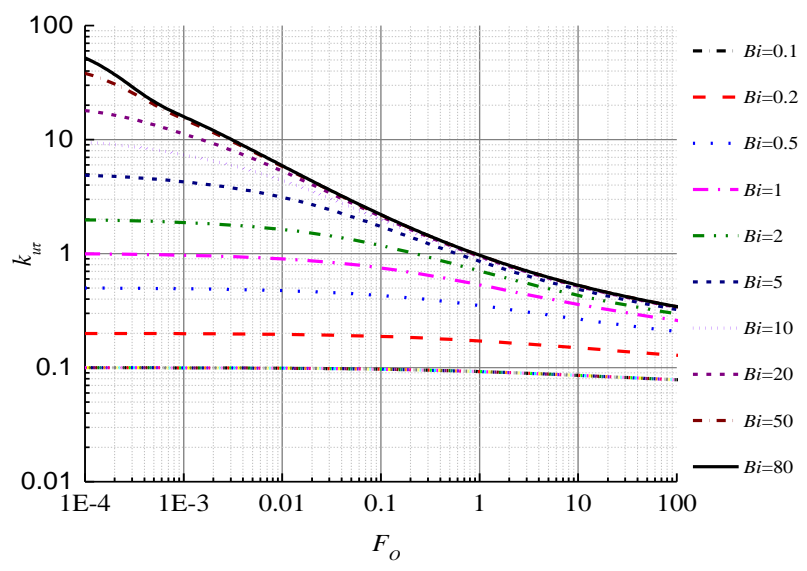

Figure 8. The unstable heat transfer criterion between roadway and air flow

\section{CONCLUSIONS}

(1) According to similarity theory, a similar simulation experiment platform for the transient temperature field of surrounding rock in roadway was established. The variation curves of dimensionless temperature with the increasing Fourier coefficient were obtained under 3 kinds of Biot coefficient. It was found that the experimental results of each point coincide well with the simulation results, and both curves were consistent with each other, which verifies the correctness of the algorithm.

(2) There are many similarities among the heat dissipation of different surrounding rocks. In this paper, dimensionless method was used to analyze the heat dissipation law of surrounding rock in roadway. The mathematical model of temperature field was established according to the Energy conservation law and Fourier law, and dimensionless mathematical model was obtained by introducing dimensionless parameters. The Finite Volume Method was used to discretize the model and the program was developed independently for calculating the transient temperature field of surrounding rock in roadway

(3) By analyzing the curve variation law of transient temperature field on wall surface, it is found that the dimensionless temperature of wall surface in roadway decreases gradually with the increase of Biot coefficient and Fourier coefficient, and finally tends to a certain value. The larger the Biot coefficient is, the smaller the dimensionless temperature of wall surface is in roadway when the Fourier coefficient is same. By analyzing variation curves of the unstable heat transfer criterion with the Fourier coefficient under different Biot coefficient, it is found that the unstable heat transfer criterion decreases with the increase of the Fourier coefficient at a constant Biot coefficient, while the unstable heat transfer criterion increases with the increase of Biot coefficient at a constant Fourier coefficient. The amplitude of variation of the unstable heat transfer criterion relative to the Fourier coefficient increases, with the increase of Biot coefficient.

(4) The curve of unstable heat transfer criterion for the transient temperature field of surrounding rock in roadway was obtained by numerical calculation. It provides a simple and reliable method to determine the unstable heat transfer criterion for the mine cooling technicians, which also provides a reliable basis for calculating the heat dissipation quantity and studying the heat dissipation law of surrounding rock in roadway.

\section{ACKNOWLEDGEMENTS}

This work was supported by the National Natural Science Foundation of China (Grant No. 51574249).

\section{REFERENCES}

[1] Loredo C, Banks D, Roqueñí N. (2017). Evaluation of analytical models for heat transfer in mine tunnels. Geothermics 69: 153-164. http://doi.org/10.1016/j.geothermics.2017.06.001

[2] Donoghue AM. (2004). Heat illness in the U.S. mining industry. Am. J. Ind. Med. 45(4): 351-356. https://doi.org/10.1002/ajim.10345

[3] Guo PY, Zhu GL, He MC. (2014). HEMS technique for heat-harm control and geo-thermal utilization in deep mines. International Journal of Coal Science and Technology 1(3): 289-296. https://doi.org/10.1007/s40789-014-0036-z

[4] Kenny GP, Vierula M, Maté J, Beaulieu F, Hardcastle SG, Reardon F. (2012). A field evaluation of the physiological demands of miners in Canada's deep mechanized mines. Journal of Occupational and Environmental Hygiene 9(8): 491-501. https://doi.org/10.1080/15459624.2012.693880

[5] Qin YP, Kong S, Liu W, Wu JS, Song HT. (2015). Dimensionless analysis of the temperature field of surrounding rock in coalface with a finite volume method. International Journal of Heat and Technology 33(3): 151-157. https://doi.org/10.18280/ ijht.330323

[6] Kalkowsky B, Kampmann B. (2006). Physiological strain of miners at hot working places in German coal mines. Ind. Health 44(3): 465-473. https://doi.org/10.2486/indhealth.44.465

[7] Wallace K, Prosser B, Stinnette JD. (2015). The practice of mine ventilation engineering. International Journal of Mining Science and Technology 25(2): 165-169. http://doi.org/10.1016/j.ijmst.2015.02.001

[8] Nikodem S, Dariusz O, Marek K. (2017). Analysis of connecting a forcing fan to a multiple fan ventilation network of a real-life mine. Process Safety and Environmental Protection 107(2): 468-479. https://doi.org/10.1016/j.psep.2017.03.001

[9] Ryan A, Euler DS. (2017). Heat stress management in underground mines. International Journal of Mining Science and Technology 27(4): 651-655. https://doi.org/10.1016/j.ijmst.2017.05.020

[10] Yang XJ, Han QY, Pang JW, Shi XW. (2011). Progress of heat-hazard treatment in deep mines. Mining Science 
and Technology (China) 21(2):

295-299.

https://doi.org/10.1016/j.mstc.2011.02.015

[11] Wu SY, Wang YM. (1989). Study on coefficient of heat transfer of tunnel wall. Uranium Mining and Metallurgy 8(4):

$55-58$.

https://doi.org/10.13426/j.Cnki.yky.1989.04. 009

[12] Wu SY, Wang YM. (1993). Study of heat and mass transfer coefficients of wet tunnel walls. Journal of China Coal Society 18(1): 41-51. https://doi.org/10.13225/j.cnki.jccs.1993.01.010

[13] Kajzar V, Pavelek Z, Koníček P, Kukutsch R. (2017). Investigation into the temperature fields of the carboniferous rock mass in the Czech part of the Upper Silesian Coal Basin. Procedia Engineering 191: 583-590. https://doi.org/10.1016/j.proeng.2017.05.221

[14] Kondjoyan A, Daudin JD. (1993). Determination of transfer coefficients by psychrometry. International Journal of Heat and Mass Transfer 36(7): 1807-1808. https://doi.org/10.1016/S0017-9310(05)80167-X

[15] Lowndes IS, Yang ZY, Jobling S, Yates C. (2006). A parametric analysis of a tunnel climatic prediction and planning model. Tunneling and Underground Space Technology 21(5): 520-532. https://doi.org/10.1016/j.tust.2005.08.012

[16] Taraba B, Slovak V, Michalec Z, Chura J. (2008). Development of oxidation heat of the coal left in the mined-out area of a long wall face: modeling using the fluent software. Journal of Mining and Metallurgy, Section B: Metallurgy 44(1): 73-81. https://doi.org/10.2298/jmmb0801073t

[17] Noureddine B, Sassi BN. (2001). Mass and heat transfer during water evaporation in laminar flow inside a rectangular channel-validity of heat and mass transfer analogy. International Journal of Thermal Science 40(1): 67-81. https://doi.org/10.1016/S1290-0729(00)01181-9

[18] Coelho PJ. (2014). Advances in the discrete ordinates and finite volume methods for the solution of radiative heat transfer problems in participating media. Journal of Quantitative Spectroscopy and Radiative Transfer 145: 121-146. https://doi.org/10.1016/j.jqsrt.2014.04.021

[19] Шербань АН. (1982). Heat transfer coefficient, unsteady heat, transfer coefficient and moisture exchange coefficient, mine cooling guide. chap. 13, China Coal Industry Publishing House, Beijing.

[20] Zhang X.X. (2000). Heat convection, thermal engineering, chap. 10, Higher Education Press, Beijing.

[21] Liu W, Song HT, Li XF. (2014). Dimensionless analysis on gas emission law around tunneling face. Journal of $\begin{array}{llll}\text { China Coal Society } & \text { 40(4): } & \text { 882-887. }\end{array}$ https://doi.org/10.13225/j.cnki.jccs.2014.3024

\section{NOMENCLATURE}

$B i$

$C_{a}$

$C_{t}$

$C_{\alpha}$

$C_{l}$

$C_{\lambda}$

$C_{u}$

$d$

$F_{O}$

$k_{u \tau}$

$k_{\tau}$

$\mathrm{Nu}$

$\mathrm{Pr}$

$Q_{l}$

$q$

$r_{0}$

$R e$

$R$

$S$

$T$

$T_{g u}$

$T_{w}$

$T_{f}$

$u$

$X$

$\Delta X$

$\Delta Y$

Y

Greek symbols

$\alpha$

$\Gamma_{1}$

$\Gamma_{2}$

$\theta$

$\theta_{\mathrm{w}}$

$\lambda$

$\lambda_{f}$

$\mu$

$\rho$ thermal diffusivity of surrounding rock specific, $\mathrm{J} /(\mathrm{kg} \cdot \mathrm{K})$

Biot coefficient

thermal diffusion similar coefficient time similar coefficient

heat convection similar coefficient

size similar coefficient

thermal conductivity similar coefficient velocity similar coefficient roadway diameter, $\mathrm{m}$

Fourier coefficient

unstable heat exchange criterion

unstable heat transfer coefficient, W/ $\left(\mathrm{m}^{2} \cdot{ }^{\circ} \mathrm{C}\right)$

Nusselt coefficient

Prandtl coefficient

the contribution of the $k$-th control volume to the energy equation of node heat dissipation strength of surrounding rock, $\mathrm{W} / \mathrm{m}^{2}$

the characteristic radius of tunnel, $m$ roadway radius, $\mathrm{m}$

Reynolds coefficient

dimensionless radius

dimensionless area of $k$-th control volume

surrounding rock temperature, ${ }^{\circ} \mathrm{C}$

original rock temperature, ${ }^{\circ} \mathrm{C}$

wall face temperature, ${ }^{\circ} \mathrm{C}$

airflow temperature, ${ }^{\circ} \mathrm{C}$

velocity of flow, $\mathrm{m} / \mathrm{s}$

dimensionless horizontal ordinate

the projected length on $X$-axis of the $k$-th control volume of node $g$ respectively the projected length on $Y$-axis of the $k$-th control volume of node $g$ respectively dimensionless vertical coordinate

thermal convectivity of surrounding rock, $\mathrm{W} /\left(\mathrm{m}^{2} \cdot{ }^{\circ} \mathrm{C}\right)$

the inside boundary of surrounding rock the outside boundary of surrounding rock dimensionless temperature

dimensionless temperature of wall surface

the heat conductivity coefficient of surrounding rock, $\mathrm{W} /\left(\mathrm{m} \cdot{ }^{\circ} \mathrm{C}\right)$

heat conductivity coefficient of air flow, $\mathrm{W} /\left(\mathrm{m} \cdot{ }^{\circ} \mathrm{C}\right)$

dynamic viscosity coefficient, $\mathrm{Pa} \cdot \mathrm{s}$

airflow density, $\mathrm{kg} / \mathrm{m}^{3}$ 